\title{
INBREEDING EFFECTS ON AVERAGE HETEROZYGOSITY IN THE SUDAN
}

\author{
N. SAHA, ${ }^{1}$ J. S. H. TAY, ${ }^{1}$ and F. S. El SheIKH ${ }^{2}$ \\ ${ }^{1}$ Department of Paediatrics, Faculty of Medicine, \\ National University of Singapore, Singapore 0511 \\ ${ }^{2}$ Central Blood Bank, Khartoum, Sudan
}

\begin{abstract}
Summary In the first series, the average heterozygosity based on ten polymorphic loci (Rhesus, MN, P, and Kell blood groups; haemoglobin; serum haptoglobin; transferrin; red cell acid phosphatase, phosphoglucomutase- 1 and glyoxalase-1) was determined among the offspring of unrelated $(n=328)$ and related (first-cousin) matings $(n=466)$ in the Sudan. The estimated average heterozygosity was found to be the same in the offspring of the first-cousin and unrelated parents $(0.3628 \pm 0.0584$ and $0.3697 \pm 0.0581$, respectively). In the second series, the average heterozygosity at five polymorphic loci (Rhesus blood group, haemoglobin, serum haptoglobin and transferrin and red cell acid phosphatase) was estimated in several tribes with variable levels of inbreeding coefficients. The estimated average heterozygosity varied from $0.14 \pm 0.09$ to $0.37 \pm 0.08$ in different tribes with varying degrees of inbreeding coefficients $\left(\alpha \times 10^{5}\right.$ of 967-3,904). However there was no significant correlation between the level of parental inbreeding with either average heterozygosity or deviation from the Hardy-Weinberg equilibrium in the offspring.
\end{abstract}

Key Words inbreeding coefficients, heterozygosity, human population, blood genetic markers

\section{INTRODUCTION}

Inbreeding results in an increased homozygosity among the offspring as they inherit the same ancestral genes. However, the effect will depend on the inbreeding coefficient as well as the number of generations for which the inbreeding has been practised (Sanghvi, 1982). Further, this will also depend on the allelic frequency at the locus. It is believed that the detrimental effects of inbreeding as a result of homozygosity may be negated if the detrimental nonviable homozygotes were eliminated in earlier generations in the case of long-standing practice. This has

Received February 28, 1989; revised version received July 17, 1989; Accepted August 3, 1989. 
been shown to be true in South Indian populations in which no appreciable inbreeding effects on fertility or morbidity were observed. (Rao and Inbaraj, 1977, 1979a, b; Hann, 1985). Similarly, we failed to observe any significant effects of inbreeding on reproductive outcome in a Sudanese population inspite of the high degree of inbreeding practised by the population (Saha and El Sheikh, 1987, Saha et al., 1989). This is further substantiated by the finding of a lack of deviation from the Hardy-Weinberg equilibrium in the phenotypic distribution of many polymorphic loci at least in three of our earlier studies on population genetics in the Sudan (Saha et al., 1978, 1979; Bayoumi et al., 1985; Bayoumi and Saha, 1987).

To our knowledge, there has been no study reported in the literature on the effect of inbreeding on the level of heterozygosity of blood genetic markers in man. We thought it worthwhile to look into this aspect of inbreeding.

\section{MATERIALS AND METHODS}

The effect of inbreeding on the average heterozygosity was studied in two different series. In the first series, the average heterozygosity was determined among the offspring of related (first-cousin) and unrelated parentage on the basis of ten polymorphic loci: Rhesus (five anti-sera), MN, P and Kell (Kk) blood groups; haemoglobin; red cell acid phosphatase, phosphoglucomutase (locus 1), glyoxalase I; serum haptoglobin and transferrin. The subjects were all healthy blood donors. Complete information of their tribal affiliation, place and year of birth, and details of parental inbreeding were recorded. It was not possible to complete the study of all the systems in all the individuals due to scarcity of facilities. Four hundred sixty-six offspring of first-cousin parentage and 328 offspring of unrelated parentage were studied for Rhesus blood groups. Much smaller but adequate numbers were investigated for other blood groups, haemoglobin, red cell enzymes, and serum protein polymorphisms.

In the second series, eight tribes and one of mixed origin with variable degrees of inbreeding in rural Sudan were investigated for the distribution of phenotypes at five polymorphic loci: Rhesus blood group, haptoglobin, transferrin, haemoglobin and red cell acid phosphatase polymorphisms. The alleleic frequencies were calculated by gene counting in all the systems except the Rhesus blood groups which was estimated by the Maximum Likelihood method using the computer programme on IBM 360 originally set by WJ Schull at the Australian National University, Canberra. The details of gene frequencies have been published earlier (Saha and El Sheikh, 1987). The inbreeding coefficients $(\alpha)$ were estimated by the formula $\sum$ piFi and expressed as $\alpha \times 10^{5}$ where $\mathrm{Fi}=$ coefficients of inbreeding, $\mathrm{pi}=$ proportion of marriages. The average heterozygosity was estimated in these tribes on the basis of five loci. The expected average heterozygosity was computed from gene frequencies using the formula $H=1-\left(p^{2}+q^{2}\right)$. Deviation from HardyWeinberg equilibrium was estimated by the $\chi^{2}$ (chi-square) test along with degrees 
Table 1. Gene frequencies and average heterozygosity (10 loci and 27 alleles) in relation to inbreeding in a Sudanese population.

\begin{tabular}{|c|c|c|c|}
\hline \multirow{2}{*}{ Systems } & & \multicolumn{2}{|c|}{ Gene frequencies } \\
\hline & & First-cousin & Unrelated \\
\hline \multirow[t]{7}{*}{ Rhesus blood groups } & $\mathrm{n}$ & 466 & 328 \\
\hline & $R z$ & 0.0063 & 0 \\
\hline & $R_{1}$ & 0.1616 & 0.1357 \\
\hline & $R_{2}$ & 0.0514 & 0.0275 \\
\hline & Ro & 0.5458 & 0.5641 \\
\hline & $\mathrm{r}^{\prime \prime}$ & 0 & 0.0181 \\
\hline & $r$ & 0.2349 & 0.2545 \\
\hline \multirow[t]{3}{*}{ MN blood groups } & $\mathrm{n}$ & 100 & 64 \\
\hline & $M$ & 0.5400 & 0.5703 \\
\hline & $N$ & 0.4600 & 0.4297 \\
\hline \multirow[t]{3}{*}{ P blood groups } & $\mathrm{n}$ & 143 & 93 \\
\hline & $P_{1}$ & 0.6078 & 0.5027 \\
\hline & $P_{2}$ & 0.3922 & 0.4973 \\
\hline \multirow[t]{3}{*}{ Kell blood groups } & $\mathrm{n}$ & 163 & 106 \\
\hline & $K$ & 0.0184 & 0.0283 \\
\hline & $k$ & 0.9816 & 0.9717 \\
\hline \multirow[t]{4}{*}{ Haemoglobin } & $\mathrm{n}$ & 174 & 164 \\
\hline & $H b^{A}$ & 0.8851 & 0.8811 \\
\hline & $H b \mathrm{~s}$ & 0.1063 & 0.1189 \\
\hline & $H b^{0}$ & 0.0086 & 0 \\
\hline \multirow[t]{4}{*}{ Acid phosphatase } & $\mathrm{n}$ & 148 & 118 \\
\hline & $p^{\mathrm{a}}$ & 0.1622 & 0.2246 \\
\hline & $p^{\mathrm{b}}$ & 0.8311 & 0.7669 \\
\hline & $p^{\mathrm{e}}$ & 0.0067 & 0.0085 \\
\hline \multirow[t]{4}{*}{ Phosphoglucomutase (1) } & $\mathrm{n}$ & 152 & 142 \\
\hline & $P G M^{1}$ & 0.4572 & 0.5214 \\
\hline & $P G M^{2}$ & 0.5395 & 0.4786 \\
\hline & $P G M^{6}$ & 0.0033 & 0 \\
\hline \multirow[t]{3}{*}{ Glyoxalase I } & $\mathrm{n}$ & 72 & 94 \\
\hline & $G L O^{1}$ & 0.7778 & 0.7553 \\
\hline & $G L O^{2}$ & 0.2222 & 0.2447 \\
\hline \multirow[t]{3}{*}{ Haptoglobin } & $\mathrm{n}$ & 121 & 109 \\
\hline & $H p^{1}$ & 0.4504 & 0.4541 \\
\hline & $H p^{2}$ & 0.5496 & 0.5459 \\
\hline \multirow[t]{3}{*}{ Transferrin } & $\mathrm{n}$ & 121 & 109 \\
\hline & $T f 0$ & 0.9053 & 0.9364 \\
\hline & $T f^{\mathrm{D}}$ & 0.0947 & 0.0636 \\
\hline Estimated average heterozygosity & & $0.3628 \pm$ & $0.3697 \pm$ \\
\hline (10 loci, 27 alleles) & & 0.0584 & 0.0581 \\
\hline
\end{tabular}

Vol. 34, No. 3, 1989 
of freedom. The relationship between average heterozygosity as well as $\chi^{2}$ and inbreeding level was estimated by the coefficient of correlation (r) test (Spearman's Rank).

\section{RESULTS AND DISCUSSION}

Table 1 shows the gene frequencies and average heterozygosity at ten polymorphic loci among the offspring of inbred (first-cousin) and unrelated parentage. The average heterozygosity was found to be the same in both the groups $(0.36 \pm$ 0.06 and $0.37 \pm 0.06$, respectively). This is contrary to expectation, as inbred offspring are thought to have excess homozygosity. This is possible only if some of the nonviable homozygous conceptions were eliminated in early pregnancy before a clinical diagnosis was possible or fresh mutations had occurred. As the foetal loss and net fertility in the Sudanese population was also the same in the inbred and outbred matings (Saha et al., 1989) - it lends further support for the exclusion of excess homozygotes in very early pregnancy. However, another interesting phenomenon emerging from the results is that the observed heterozygosity is marginally less than the expected heterozygosity in both the groups. This may be explained by the following: i) probably a balance has been attained by the establishment of a new equilibrium with slightly less heterozygosity and maintained at this level; ii) the inadequacy of the methods used to identify heterozygotes completely; iii) the small size and heterogeneity of the sample.

Table 2 shows another set of data on the average heterozygosity at five poly-

Table 2. Average heterozygosity, Hardy-Weinberg equilibrium and inbreeding coefficients in eight Sudanese tribes.

\begin{tabular}{lrrrrrr}
\hline Tribe & $\mathrm{n}$ & \multicolumn{1}{c}{$\chi^{2}$} & d.f. & $\chi^{2} /$ d.f. & $\begin{array}{c}\alpha \\
\left(\times 10^{5}\right)\end{array}$ & $\begin{array}{c}\text { Average } \\
\text { heterozygosity }\end{array}$ \\
\hline Nuba & 137 & 74.83 & 16 & 4.68 & 2,629 & $0.1996 \pm 0.0786$ \\
Für & 48 & 74.41 & 21 & 3.53 & 2,706 & $0.3484 \pm 0.0880$ \\
Nilotes & 47 & 13.88 & 11 & 1.26 & 967 & $0.1450 \pm 0.0922$ \\
Gäalin & 147 & 128.66 & 23 & 5.59 & 3,904 & $0.3173 \pm 0.1185$ \\
Hawazma & 38 & 74.02 & 21 & 3.52 & 2,148 & $0.3356 \pm 0.0953$ \\
Messeria & 141 & 13.27 & 20 & 0.66 & 3,517 & $0.3702 \pm 0.0775$ \\
Dongolai & 40 & 25.38 & 20 & 1.27 & 3,409 & $0.2982 \pm 0.1074$ \\
Others & 116 & 71.59 & 21 & 3.40 & 3,546 & $0.2897 \pm 0.1218$ \\
\hline
\end{tabular}

Correlation coefficients (Spearman rank): $\chi^{2}$ and $\alpha=0.19, \chi^{2} /$ d.f. and $\alpha=0.19$. Average heterozygosity and $\alpha=0.33$. Gene frequencies were taken from Saha and El Sheikh (1987). (Based on five loci-Rhesus, haptoglobin, transferrin, haemoglobin and acid phosphatase). Inbreeding coefficients were estimated using the formula: $\alpha=\sum$ piFi. Expected average heterozygosity was estimated using the formula: $\mathrm{H}=1-\left(\mathrm{p}^{2}+\mathrm{q}^{2} \ldots \ldots\right)$. 
morphieloci in several tribal groups with variable levels of coefficients of inbreeding. The estimated average heterozygosity ranged from $0.14 \pm 0.09$ to $0.37 \pm 0.08$ while the inbreeding coefficients $\left(\alpha \times 10^{5}\right)$ varied from 967 to 3,904 in different tribes. However, the degree of inbreeding coefficients did not have any significant correlation with either the average heterozygosity or deviation from the Hardy-Weinberg equilibrium. The results of both the series suggest a lack of any influence of inbreeding on average heterozygosity based on blood genetic markers in the Sudanese population.

The above results demonstrate that the average heterozygosity in a population with a high degree of inbreeding practised over many generations is maintained at an optimal level probably by elimination of nonviable homozygotes at an early stage, even before the pregnancy can be detected. This is also consistent with the lack of inbreeding effects on the reproductive profiles observed in the Sudanese and South Indian populations and the lack of expected deviation from the HardyWeinberg equilibrium in the phenotypic distribution of blood genetic markers in several earlier studies in the Sudanese population (Saha et al., 1978, 1979; Bayoumi et al., 1985; Bayoumi and Saha, 1987).

\section{REFERENCES}

Bayoumi, R.A. and Saha, N. 1987. Some genetic characteristics of the Nuba and Hawazma tribes of the Sudan. Am. J. Phys. Anthropol. 73: 379-388.

Bayoumi, R.A., Taha, T.S.M. and Saha, N. 1985. A genetic study among the Fur and Baggara tribes in Gabal Merrah, the Sudan. Am. J. Phys. Anthropol. 67: 363-370.

Hann, K.L. 1985. Inbreeding and fertility in a South Indian population. Ann. Hum. Biol. 12: 267-274.

Rao, P.S.S.S. and Inbaraj, S.G. 1977. Inbreeding effects on human reproduction in Tamil Nadu of South India. Ann. Hum. Genet. 41:87-98.

Rao, P.S.S.S. and Inbaraj, S.G. 1979a. Trends in human reproductive wastage in relation to longterm practice of inbreeding. Ann. Hum. Genet. 42: 401-413.

Rao, P.S.S.S. and Inbaraj, S.G. 1979b. Inbreeding effects on fertility and sterility in Southern India. J. Med. Genet. 16: 24-31.

Saha, N. and E1 Sheikh, F.S. 1987. Some blood genetic characteristics of several Sudanese tribes. Am. J. Phys. Anthropol. 73: 397-406.

Saha, N. and El Sheikh, F.S. 1988. Inbreeding levels in Khartoum. J. Biosoc. Sci. 20: 333-336.

Saha, N., Gumaa, K.A., Samuel, A.P.W. and El-Naeim, H. 1979. Placental alkaline phosphatase in a Sudanese population: polymorphism and enzyme activity. Hum. Biol. 51: 335-339.

Saha, N., Hamad, R.E. and Mohamed, S. 1989. Inbreeding effects on reproductive outcome in a Sudanese population. Hum. Hered. in press.

Saha, N., Samuel, A.P.W., Omer, A., Ahmed, M.A., Hussein, A.A. and El Nour Gaddoura, N. 1978. A study of some genetic characteristics of the population of the Sudan. Ann. Hum. Biol. 5: $569-575$.

Sanghvi, L.D. 1982. Inbreeding in India. Soc. Biol. 29: 106-117. 